\title{
The Hypothalamic Preoptic Area and Body Weight Control
}

\author{
Sangho Yu Marie François Clara Huesing Heike Münzberg \\ Neurobiology of Nutrition and Metabolism Department, Pennington Biomedical Research Center, Louisiana State \\ University System, Baton Rouge, LA, USA
}

\section{Keywords}

Temperature-dependent adaptation · Thermoregulation · Energy homeostasis · Food intake · Energy expenditure

\begin{abstract}
The preoptic area (POA) of the hypothalamus is involved in many physiological and behavioral processes thanks to its interconnections to many brain areas and ability to respond to diverse humoral factors. One main function of the POA is to manage body temperature homeostasis, e.g. in response to ambient temperature change, which is achieved in part by controlling brown adipose tissue thermogenesis. The POA is also importantly involved in modulating food intake in response to temperature change, thus making it relevant for body weight homeostasis and obesity research. POA function in body weight control is highly unexplored, and a better understanding of POA circuits and their integration into classic hypothalamic circuits that regulate energy homeostasis is expected to provide new opportunities for the scientific basis and treatment of obesity and comorbidities.
\end{abstract}

(c) 2017 S. Karger AG, Basel

\section{KARGER}

๑ 2017 S. Karger AG, Basel

E-Mail karger@karger.com

www.karger.com/nen

\section{Introduction}

The preoptic area (POA) is involved in various physiological regulations that are essential for survival. One prominent role of the POA is to control physiological adaptations to ambient temperature changes, including robust modulation in energy expenditure and food intake [1-3]. Traditionally, the POA is not associated with body weight control, but its major role in temperature-dependent metabolic adaptations warrants further investigation and discussion on the interaction between the POA and body weight homeostasis. Recent studies have used sophisticated genetic and molecular tools to shed new light on the physiological function of the POA and confirmed the robust effect of the POA on energy expenditure [3-6]. Most notably, POA-mediated metabolic adaptations also induced food intake and body weight changes [3]. These results highlight the POA as a site of body weight modulation, but also raise the question of how temperature-dependent metabolic adaptations may affect body weight. In this review, we briefly summarize old and new studies of the POA with special emphasis on its 


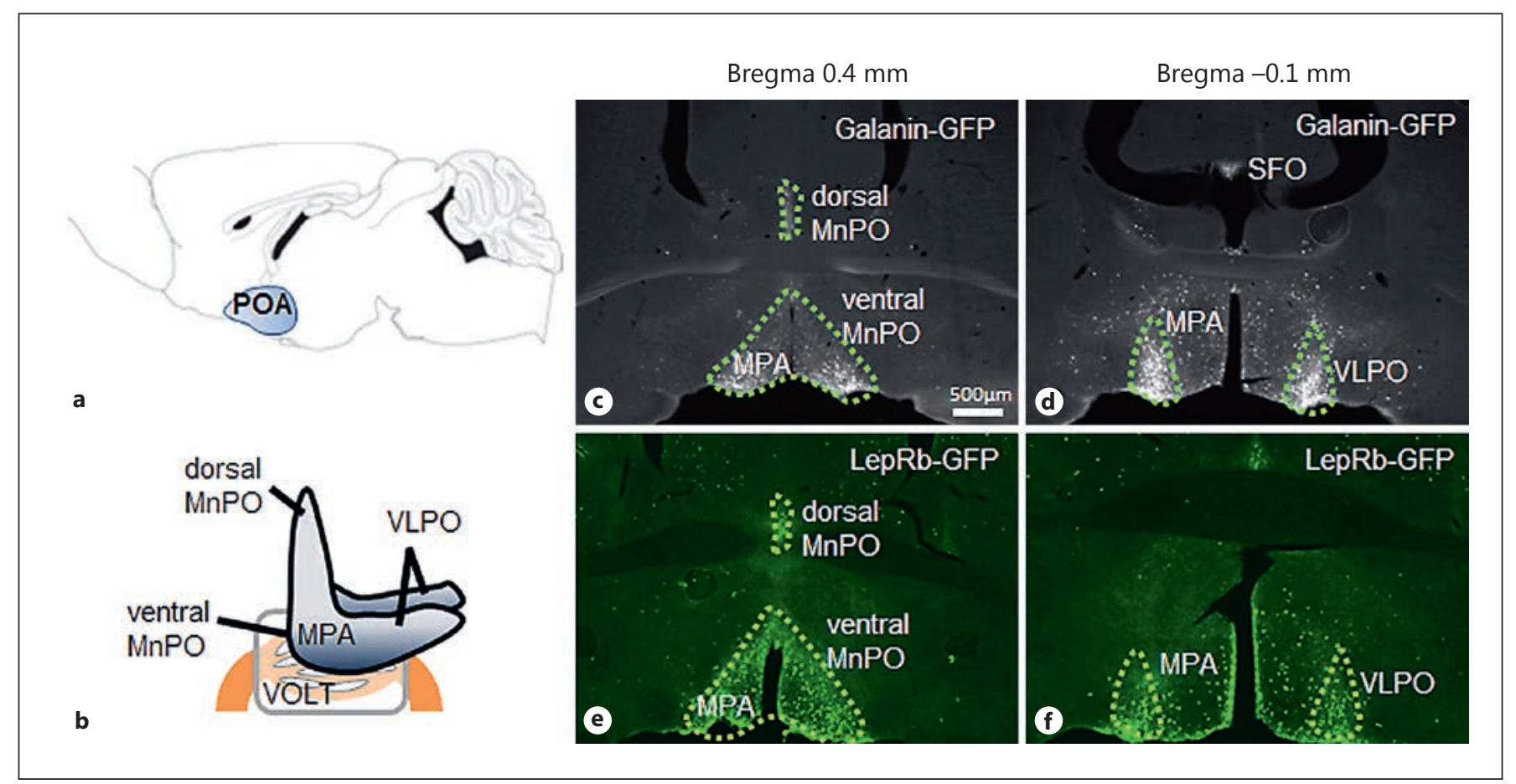

Fig. 1. a Sagittal scheme of the mouse brain highlighting the gross location of the preoptic area (POA) within the CNS. b-f The POA is associated with the vascular organ of the lamina terminalis (VOLT) and the subfornical organ (SFO), both circumventricular organs that allow access and exchange with the circulation. Fur-

role in energy homeostasis. We will further discuss future studies needed to explore the role of the POA in body weight control and its potential to improve therapies in humans with metabolic dysfunction.

\section{The POA and Homeostasis}

The POA is an important site for several homeostatic regulations like sleep, osmolarity, reproduction, and body temperature (see [7] for a comprehensive review). While all the aforementioned systems impact food intake and energy expenditure, the POA has not been specifically linked to body weight control in studies of these parameters.

Anatomically, the POA encloses the vascular organ of the lamina terminalis (VOLT) and is connected with the subfornical organ (SFO), and both VOLT and SFO are classic circumventricular organs that lack a typical blood brain barrier (Fig. 1) [8-12]. Thus, the POA is well positioned for bidirectional communication with circulating thermore, several subareas can be distinguished in the POA that are well visualized by galanin- or leptin receptor (LepRb)-expressing neurons: dorsal and ventral median preoptic area $(\mathrm{MnPO})$, medial preoptic area (MPA), and the ventrolateral preoptic area (VLPO).

factors. Within this rostro-caudal extent, several subareas are distinguished in the POA: median preoptic nucleus (MnPO), medial POA, and ventrolateral preoptic nucleus (VLPO) (Fig. 1b). The anatomical extent of the POA is nicely demarcated by neurons that express leptin receptors (LepRb) or the neuropeptide galanin (Fig. 1c-f). Both LepRb and galanin are associated with modulation of feeding and body weight $[13,14]$, but their functional importance in the POA is not well understood.

Different POA subareas are associated with distinct homeostatic functions and connected with other hypothalamic sites that are known for their role in body weight homeostasis. For example, the VLPO is involved in the regulation of sleep-wake cycles and expresses the inhibitory neurotransmitter GABA as well as galanin $[15,16]$. These GABAergic VLPO projections innervate orexin/ hypocretin neurons in the lateral hypothalamic area (LHA) to initiate and maintain sleep [17]. However, the orexin/hypocretin system also promotes locomotor activity and food reward [18]. 
The SFO $>\mathrm{MnPO}$ and VOLT $>\mathrm{MnPO}$ connections are important regulators of osmotic homeostasis [7]. Two populations of SFO neurons are important for their opposing effects on induction and inhibition of thirst, and these signals are propagated via $\mathrm{SFO}>\mathrm{MnPO}$ neuronal circuits [19]. Thirst is closely tied to feeding with the reciprocal regulation of thirst/osmolarity and hunger. In other words, changes in thirst or osmolarity modulate feeding and vice versa [20-22], even though the neuronal basis for this interaction has not yet been explored.

The POA is also an important regulator of reproductive function. LepRb, the receptor for the adipose tissuederived hormone leptin, is an important homeostatic regulator of body weight and reproduction [23, 24] and is strongly expressed in the POA (Fig. 1e, f). Leptin communicates with the brain as a signal for sufficient energy stores for reproduction, and low leptin levels prevent reproduction in animal models and humans [25]. This leptin effect on reproduction is thought to be mediated via neurons coexpressing LepRb and neuronal nitric oxide synthase in the POA and the ventral premammillary nucleus through increasing the secretion of gonadotropin-releasing hormone and in turn, luteinizing hormone [26-29].

Finally, the POA has robust effects on body temperature homeostasis. The POA is associated with various autonomic responses for heat production, retention, and loss, such as brown adipose tissue (BAT) thermogenesis, sweating, shivering, and vasomotion [30-32]. Ambient warm or cold temperature stimulates distinct POA neurons, and efferent neural circuits from these neurons are connected to brain areas and effector organs involved in body temperature regulation [33-40]. Notably, the POA is involved in BAT thermoregulation which is of particular interest as a potential therapeutic target for obesity and metabolic disease $[41,42]$. Because the POA's role in thermoregulation, along with modulation of food intake, is most relevant to body weight control, we will further discuss this aspect in the following section.

\section{The POA in Thermoregulation and Energy Homeostasis}

\section{An Overview of Thermoregulatory POA Neurons}

Cold or warm ambient temperature is first sensed by peripheral thermoreceptors in the skin. These thermosensory signals are transmitted via thermal afferent pathways to the POA in "feed-forward" mechanisms that adjust physiological settings in an effort to prevent antici-

The Hypothalamic Preoptic Area and Body Weight Control pated core body temperature changes [43]. The viscera also contain thermoreceptors to communicate changes in core temperature to the POA, in situations like fever and hypothermia. The POA in turn modulates the central thermoregulatory network to ultimately control the sympathetic output to various organs including BAT and white adipose tissue, skin blood vessels, and heart [1].

Warm and cold ambient temperature both stimulate POA neurons $[3,4,6,33,35,37,38,44]$ by activating warm- or cold-sensitive neurons (WS or CS), respectively. Neuronal cold sensitivity may be due to decreased synaptic inhibition onto CS neurons by WS GABAergic neurons [45-47]. On the other hand, different studies suggested that the cold response is mediated by inhibiting major WS effector neurons by GABAergic CS neurons within the POA $[48,49]$. Thus, it is likely that a combination of reciprocal inhibitions within the POA between WS and CS neurons is driving neuronal cold and warm sensitivity.

\section{Warm-Sensitive POA Neurons and Energy \\ Homeostasis}

GABAergic WS POA neurons inhibit downstream CS neurons in the dorsomedial hypothalamic nucleus (DMH) that initiate thermoregulatory responses such as BAT thermogenesis [50-53]. A recent study performed a molecular profiling of WS POA neurons and identified WS POA neurons that coexpress the neuropeptides pituitary adenylate cyclase-activating peptide (PACAP; official gene nomenclature name is ADCYAP1) and brainderived neurotrophic factor (BDNF) [4]. The projection of these WS POA PACAP/BDNF neurons to the DMH is GABAergic and optogenetic stimulation of this POA> $\mathrm{DMH}$ projection decreases body temperature, consistent with an inhibitory effect on CS DMH neurons [4]. We speculate that POA PACAP/BDNF neurons may inhibit LepRb neurons in the $\mathrm{DMH}$ (LepRb ${ }^{\mathrm{DMH}}$ neurons), as LepRb ${ }^{\mathrm{DMH}}$ neurons are activated by cold temperature [54] and their chemogenetic activation increases body temperature [55]. Interestingly, chronic activation of LepRb ${ }^{\mathrm{DMH}}$ neurons over 3 days significantly decreased body weight in mice due to increased energy expenditure without an effect on food intake [55], suggesting that POA inputs to the DMH may be capable of modulating body weight.

Another population of WS POA neurons express Lep$\mathrm{Rb}$ (LepRb ${ }^{\mathrm{POA}}$ neurons) and they are mostly glutamatergic [3]. Chemogenetic activation of either LepRb-expressing or glutamatergic POA neurons caused a robust decrease in energy expenditure that resulted in a deep hypothermia 


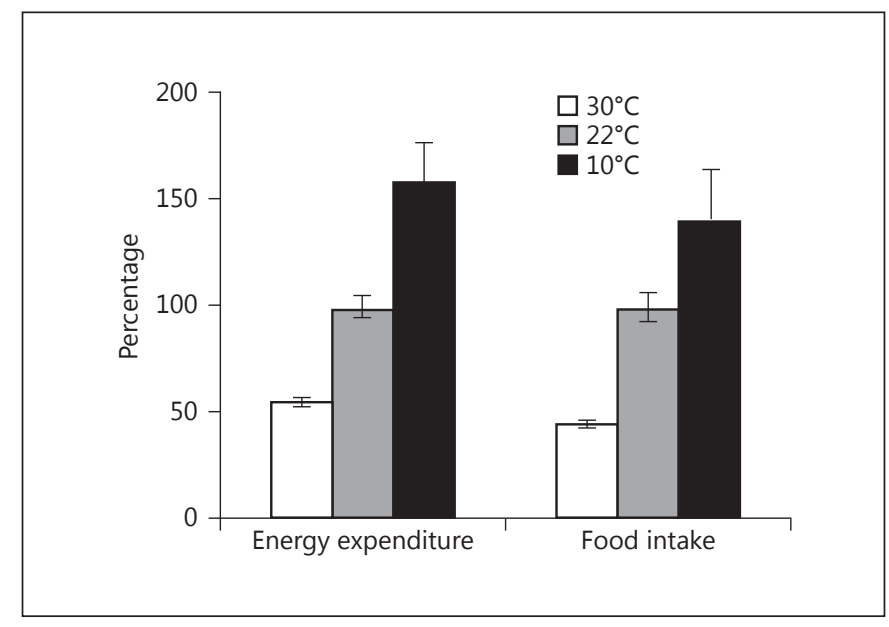

Fig. 2. Ambient temperature change strongly affects both energy expenditure and food intake in mice. Ambient warm temperature decreases, while cold increases energy expenditure and food intake.

(body temperature decrease of $6^{\circ} \mathrm{C}$ ). Importantly, chronic activation of LepRb ${ }^{\mathrm{POA}}$ neurons decreased food intake as well as energy expenditure, which leads to body weight loss, again suggesting a role of the POA in modulating metabolic rate, food intake, and body weight. Further investigation of these glutamatergic LepRb ${ }^{\mathrm{POA}}$ neurons at different ambient temperature demonstrated that the metabolic suppression was ambient temperature dependent [3]. These data strongly suggest that LepRb ${ }^{\mathrm{POA}}$ neurons mediate physiological adaptations in response to ambient temperature changes. LepRb ${ }^{\mathrm{POA}}$ neurons may coexpress transient receptor potential cation channel M2 (TRPM2) because TRPM2 ${ }^{\mathrm{POA}}$ neurons are also glutamatergic WS neurons, and chemogenetic activation of TRPM $2^{\mathrm{POA}}$ neurons induces a similar deep hypothermia as observed with LepRb ${ }^{\mathrm{POA}}$ neurons [5]. TRPM2 ${ }^{\mathrm{POA}}$ neurons project to and activate PVH neurons, and TRPM2 seems to be important for translating local warming into neuronal activation as preoptic prostaglandin E2-evoked febrile response was exaggerated in mice lacking TRPM2 [5].

\section{The POA in Temperature-Dependent Adaptations and Body Weight Control}

\section{The POA Interaction with the Body Weight}

Homeostatic System

As noted earlier, ambient temperature strongly modulates food intake in addition to energy expenditure
(Fig. 2), likely as an effort to counterbalance the changed energy expenditure level by adjusting the amount of food consumption accordingly. This bimodal regulation is important as an excessive increase or decrease in energy expenditure observed during cold or warm exposure, respectively, would undoubtedly lead to body weight loss (cold temperature) or gain (warm temperature). Thus, the interaction between energy expenditure and food intake ensures body temperature homeostasis without compromising body weight homeostasis. The POA has been neglected from the discussion of body weight control mainly due to the lack of obvious food intake or body weight phenotypes from classical brain lesion studies, unlike the ventromedial nucleus of the hypothalamus, arcuate nucleus (ARC), or LHA [56-58].

However, the involvement of the POA in modulation of temperature-dependent food intake was first described several decades ago in goats and rats [2, 31, 59]. These studies demonstrated the interaction between 2 homeostatic systems regulating body temperature and body weight, and implicated the critical role of the POA in that interaction. For example, experimental cooling of the POA increased body temperature and food intake, while experimental warming of the POA had the opposite effect [2]. When the rostral hypothalamic area spanning the POA was damaged, rats had difficulty maintaining core temperature and adapting food intake upon ambient temperature changes $[31,59]$. Notably, POA-lesioned rats showed normal food intake at typical housing temperature of $20-24^{\circ} \mathrm{C}$ but failed to adapt their food intake properly with changes in ambient temperature. However, the role of the POA in food intake modulation has not been explored further until recently when it was shown that the degree of LepR $\mathrm{R}^{\mathrm{POA}}$ neuronal activation reflects the degree of suppression of energy expenditure and food intake [3].

These data reveal a specific role of the POA in temperature-dependent adjustment of food intake and suggest that the change in food intake may not be a secondary effect of the change in energy expenditure, but a direct function of the POA. Although we currently do not know how the POA modulates food intake, POA neurons innervate several brain areas that are involved in the modulation of feeding behavior (Fig. 3), such as the ARC, paraventricular hypothalamic nucleus (PVH), LHA, and ventral DMH $[4,60,61]$. Recent technical advances such as optogenetics and chemogenetics should be instrumental in functionally dissecting different effector pathways controlled by the POA.

POA neurons not only innervate feeding-related areas but also receive inputs from those areas. The ARC is the 


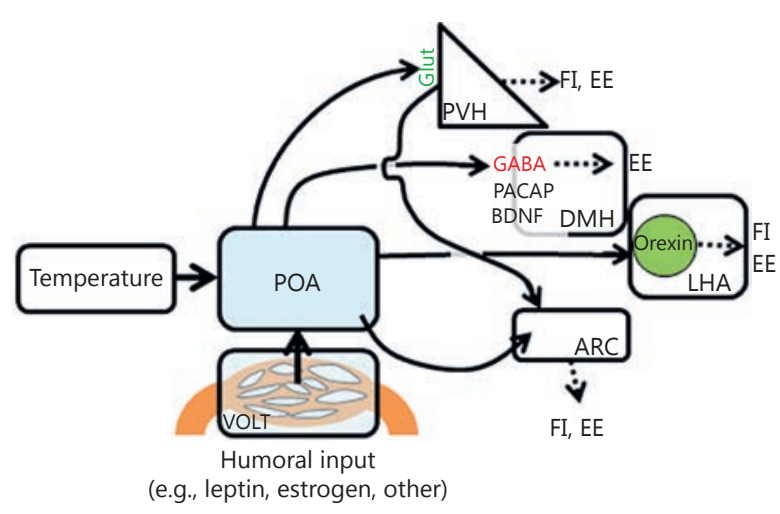

Fig. 3. Schematic drawing to depict environmental challenges that may modulate food intake (FI) or energy expenditure (EE) via the preoptic area (POA) and $\mathrm{POA}>$ hypothalamus projections that could potentially mediate metabolic adaptations of FI or EE as outlined in this review. VOLT, vascular organ of the lamina terminalis; PVH, paraventricular hypothalamic nucleus; $\mathrm{DMH}$, dorsomedial hypothalamus, LHA, lateral hypothalamic area; ARC, arcuate nucleus; Glut, glutamate; GABA, $\gamma$-aminobutyric acid; PACAP, pituitary adenylate cyclase-activating peptide; BDNF, brain-derived neurotrophic factor.

hypothalamic site best known for its role in the regulation of food intake via 2 opposing neuronal populations, orexigenic agouti-related neuropeptide (AGRP) neurons and anorexigenic pro-opiomelanocortin (POMC) neurons. Energy expenditure decreases with stimulation of AGRP neurons [62], while it increases with stimulation of POMC neurons [63]. Conversely, AgRP and POMC neurons both also send axon fibers to the POA where AgRP and $\mathrm{POMC}$ can act via their receptor, melanocortin 4 receptor (MC4R) [60]. The injection of the MC4R agonist, melanotan II, into the POA stimulates BAT thermogenesis and is blocked by DMH lesions [64], implicating that the melanocortin system may utilize the classical BAT thermoregulatory pathway to modulate the metabolic rate in response to energy status changes. Another population of ARC neurons was identified by Cre expression under the control of rat insulin promoter (RIP). These GABAergic RIP-Cre neurons are separate from AGRP or POMC neurons, respond to leptin and modulate BAT thermogenesis through their projection to the PVH [65].

Orexin/hypocretin-expressing neurons in the LHA are another hypothalamic population that is well known to promote appetite and food reward [66, 67], but also stimulates BAT thermogenesis through direct innerva- tion of the rostral medullary raphe (RMR) $[68,69]$. In short, some neuronal populations that are well known for their role in food intake control either project directly to the $\mathrm{POA}$ or interject the classical $\mathrm{POA}>\mathrm{DMH}>\mathrm{RMR}$ thermoregulatory circuit to affect energy expenditure [43].

\section{Signal Integration at the $P O A$}

The POA receives many neuronal and humoral inputs that are not related to skin temperature or energy state. Its heavy connectivity with 2 proximal circumventricular areas, the VOLT and the SFO, makes the POA ideally positioned to respond to various humoral factors [7]. The expression profile of receptors for hormones, neuropeptides, neurotransmitters, and other signaling molecules on POA neurons suggests the diverse repertoire of systems the POA may interact with [4, 54, 70-76]. Based on electrophysiological and neural tracing data, it has been proposed that some POA neurons are capable of responding to multiple stimuli, providing a mechanistic basis for signal integration $[7,77]$. For instance, certain POA neurons that project to the PVH respond to hypertonicity, angiotensin II, and baroreceptor input to synchronously modulate cardiovascular function [78]. Other studies showed similar findings in which some thermosensitive POA neurons responded to glucose and/or osmotic pressure $[77,79,80]$. This integration of multiple stimuli is critical for coordinated physiological responses to maximize the animal's chance of survival. For example, rodents at high ambient temperature increase salivation and licking behavior to enhance heat loss [81]. Salivation and licking both increase water loss that needs to be replenished with fluid intake, explaining the physiological importance of coordinating multiple physiological systems to meet both thermo- and osmoregulatory needs.

Similarly, the reproductive hormone estrogen suppresses food intake via estrogen receptor-a (Esr1)-expressing neurons, including Esr1 neurons in the POA [82]. Many POA neurons coexpress LepRb and Esr1 [83], providing a potential integration of estrogen and leptin signaling in the POA for body weight control. Leptin signaling in the POA contributes to body weight modulation under a high-fat diet condition in mice, in which the circulating leptin level is high [our own unpubl. data]. Thus, LepRb ${ }^{\mathrm{POA}}$ neurons may possibly integrate several signals (i.e., leptin, estrogen, and ambient temperature) and modulate body weight under distinct conditions. 


\section{Conclusions and Perspectives}

The POA is a major integration site of various physiological and environmental signals and coordinates balanced responses to maximize the chance of survival. With the ongoing rise in obesity and the realization that lifestyle intervention with diets and exercise fails to improve obesity in the long term, we need a more holistic thinking about body weight regulation. BAT thermogenesis is currently intensely explored as a possible target to improve body weight and metabolic health. However, metabolic changes in response to ambient temperature are not integrated into our current understanding of body weight homeostasis. The POA is an essential brain area for the sensation of ambient temperature, and the involvement of the POA in food intake and energy expenditure highlights the POA as highly relevant for obesity research. Further studies are required to identify the exact neuronal circuits involved in ambient temperature-dependent metabolic adaptations and whether these circuits integrate into traditional hypothalamic circuits of metabolic regulation or if they form independent parallel circuits. A better understanding of POA circuits could provide new therapeutic strategies that impinge on both food intake and energy expenditure.

\section{Acknowledgements}

This work was supported by P20 RR02195, P/F NORC \#2P30DK072476-06, R01DK092587 (H.M.), 2P20 GM103528 (S.Y.), and 1-OT2OD023864-01 (H.M., S.Y.). This work utilized the facilities of the Cell Biology and Bioimaging Core, supported in part by COBRE (NIH P20-RR021945) and CNRU (NIH 1P30-DK072476) center grants from the National Institutes of Health. Partial support was provided through the Animal Phenotyping Core supported through NIDDK NORC Center Grant \#2P30 DK072476 entitled "Nutritional Programming: Environmental and Molecular Interactions" at the Pennington Biomedical Research Center.

\section{References}

1 Nakamura K: Central circuitries for body temperature regulation and fever. Am J Physiol Regul Integr Comp Physiol 2011; 301:R1207-R1228.

2 Andersson B, Larsson B: Influence of local temperature changes in the preoptic area and rostral hypothalamus on the regulation of food and water intake. Acta Physiol Scand 1961;52:75-89.

3 Yu S, Qualls-Creekmore E, Rezai-Zadeh K, Jiang Y, Berthoud HR, Morrison CD, Derbenev AV, Zsombok A, Munzberg H: Glutamatergic preoptic area neurons that express leptin receptors drive temperature-dependent body weight homeostasis. J Neurosci 2016;36: 5034-5046.

4 Tan CL, Cooke EK, Leib DE, Lin YC, Daly GE, Zimmerman CA, Knight ZA: Warm-sensitive neurons that control body temperature. Cell 2016;167:47-59.

5 Song K, Wang H, Kamm GB, Pohle J, Reis FC, Heppenstall P, Wende H, Siemens J: The TRPM2 channel is a hypothalamic heat sensor that limits fever and can drive hypothermia. Science 2016;353:1393-1398.

6 Zhao ZD, Yang WZ, Gao C, Fu X, Zhang W, Zhou Q, Chen W, Ni X, Lin JK, Yang J, et al: A hypothalamic circuit that controls body temperature. Proc Natl Acad Sci USA 2017; 114:2042-2047.

7 McKinley MJ, Yao ST, Uschakov A, McAllen RM, Rundgren M, Martelli D: The median preoptic nucleus: front and centre for the regulation of body fluid, sodium, temperature, sleep and cardiovascular homeostasis. Acta Physiol (Oxf) 2015;214:8-32.
8 Miselis RR, Shapiro RE, Hand PJ: Subfornical organ efferents to neural systems for control of body water. Science 1979;205:1022-1025.

9 Thompson R: Structural characterization of a hypothalamic visceromotor pattern generator network. Brain Res Rev 2003;41:153-202.

10 Saper CB, Levisohn D: Afferent connections of the median preoptic nucleus in the rat: anatomical evidence for a cardiovascular integrative mechanism in the anteroventral third ventricular (AV3V) region. Brain Res 1983; 288:21-31.

11 Langlet F, Mullier A, Bouret SG, Prevot V, Dehouck B: Tanycyte-like cells form a bloodcerebrospinal fluid barrier in the circumventricular organs of the mouse brain. J Comp Neurol 2013;521:3389-3405.

12 Prager-Khoutorsky M, Bourque CW: Anatomical organization of the rat organum vasculosum laminae terminalis. Am J Physiol Regul Integr Comp Physiol 2015;309:R324R337.

13 Münzberg H, Morrison CD: Structure, production and signaling of leptin. Metabolism 2015;64:13-23.

14 Barson JR, Morganstern I, Leibowitz SF: Galanin and consummatory behavior: special relationship with dietary fat, alcohol and circulating lipids. EXS 2010;102:87-111.

15 Sherin JE, Elmquist JK, Torrealba F, Saper CB: Innervation of histaminergic tuberomammillary neurons by GABAergic and galaninergic neurons in the ventrolateral preoptic nucleus of the rat. J Neurosci 1998;18:4705-4721.
16 Sherin JE, Shiromani PJ, McCarley RW, Saper CB: Activation of ventrolateral preoptic neurons during sleep. Science 1996;271:216-219.

17 Inutsuka A, Yamanaka A: The physiological role of orexin/hypocretin neurons in the regulation of sleep/wakefulness and neuroendocrine functions. Front Endocrinol (Lausanne) 2013;4:18.

18 Berthoud H-R, Münzberg H: The lateral hypothalamus as integrator of metabolic and environmental needs: from electrical self-stimulation to opto-genetics. Physiol Behav 2011; 104:29-39.

19 Oka Y, Ye M, Zuker CS: Thirst driving and suppressing signals encoded by distinct neural populations in the brain. Nature 2015;520: 349-352.

20 Rolls BJ: Interaction of hunger and thirst in rats with lesions of the preoptic area. Physiol Behav 1975; 14:537-543.

21 Singer G, Kelly J: Cholinergic and adrenergic interaction in the hypothalamic control of drinking and eating behavior. Physiol Behav 1972;8:885-890.

22 Zimmerman CA, Lin YC, Leib DE, Guo L, Huey EL, Daly GE, Chen Y, Knight ZA: Thirst neurons anticipate the homeostatic consequences of eating and drinking. Nature 2016; 537:680-684

23 Friedman JM: Leptin and the regulation of body weight. Keio J Med 2011;60:1-9.

24 Nestor CC, Kelly MJ, Ronnekleiv OK: Crosstalk between reproduction and energy homeostasis: central impact of estrogens, leptin and kisspeptin signaling. Horm Mol Biol Clin Investig 2014;17:109-128. 
25 Evans MC, Anderson GM: Neuroendocrine integration of nutritional signals on reproduction. J Mol Endocrinol 2017;58:R107R128.

26 Donato J, Cravo RM, Frazão R, Gautron L, Scott MM, Lachey J, Castro IA, Margatho LO, Lee S, Lee C, et al: Leptin's effect on puberty in mice is relayed by the ventral premammillary nucleus and does not require signaling in Kiss1 neurons. J Clin Invest 2011;121:355368.

27 Bellefontaine N, Chachlaki K, Parkash J, Vanacker C, Colledge W, d'Anglemont de Tassigny X, Garthwaite J, Bouret SG, Prevot $\mathrm{V}$ : Leptin-dependent neuronal NO signaling in the preoptic hypothalamus facilitates reproduction. J Clin Invest 2014;124:25502559.

28 Donato J, Jr, Frazao R, Fukuda M, Vianna CR, Elias CF: Leptin induces phosphorylation of neuronal nitric oxide synthase in defined hypothalamic neurons. Endocrinology 2010; 151:5415-5427.

29 Hanchate NK, Parkash J, Bellefontaine N, Mazur D, Colledge WH, d'Anglemont de Tassigny X, Prevot V: Kisspeptin-GPR54 signaling in mouse NO-synthesizing neurons participates in the hypothalamic control of ovulation. J Neurosci 2012;32:932-945.

30 Beaton LE, McKinley WA, Berry CM, Ranson SW: Localization of cerebral center activating heat-loss mechanisms in monkeys. J Neurophysiol 1941;4:478-485.

31 Hamilton CL, Brobeck JR: Food intake and temperature regulation in rats with rostral hypothalamic lesions. Am J Physiol 1964;207: 291-297.

32 Boulant JA, Hardy JD: The effect of spinal and skin temperatures on the firing rate and thermosensitivity of preoptic neurones. J Physiol 1974;240:639-660.

33 Scammell TE, Price KJ, Sagar SM: Hyperthermia induces c-fos expression in the preoptic area. Brain Res 1993;618:303-307.

34 Bamshad M, Song CK, Bartness TJ: CNS origins of the sympathetic nervous system outflow to brown adipose tissue. Am J Physiol 1999;276:R1569-1578.

35 Hubschle T, Mathai ML, McKinley MJ, Oldfield BJ: Multisynaptic neuronal pathways from the submandibular and sublingual glands to the lamina terminalis in the rat: a model for the role of the lamina terminalis in the control of osmo- and thermoregulatory behavior. Clin Exp Pharmacol Physiol 2001; 28:558-569.

36 Oldfield BJ, Giles ME, Watson A, Anderson C, Colvill LM, McKinley MJ: The neurochemical characterisation of hypothalamic pathways projecting polysynaptically to brown adipose tissue in the rat. Neuroscience 2002; 110:515-526.

37 Yoshida K, Maruyama M, Hosono T, Nagashima K, Fukuda Y, Gerstberger R, Kanosue $\mathrm{K}$ : Fos expression induced by warming the preoptic area in rats. Brain Res 2002;933:109_ 117.
38 Cano G, Passerin AM, Schiltz JC, Card JP, Morrison SF, Sved AF: Anatomical substrates for the central control of sympathetic outflow to interscapular adipose tissue during cold exposure. J Comp Neurol 2003;460:303-326.

39 Tanaka M, McKinley MJ, McAllen RM: Roles of two preoptic cell groups in tonic and febrile control of rat tail sympathetic fibers. Am J Physiol Regul Integr Comp Physiol 2009; 296:R1248-R1257.

40 Tanaka M, McKinley MJ, McAllen RM: Preoptic-raphé connections for thermoregulatory vasomotor control. J Neurosci 2011;31: 5078-5088.

41 Harms M, Seale P: Brown and beige fat: development, function and therapeutic potential. Nat Med 2013;19:1252-1263.

42 Bartelt A, Heeren J: Adipose tissue browning and metabolic health. Nat Rev Endocrinol 2014;10:24-36.

43 Morrison S, Madden C, Tupone D: Central neural regulation of brown adipose tissue thermogenesis and energy expenditure. Cell Metab 2014;19:741-756.

44 Bratincsak A, Palkovits M: Activation of brain areas in rat following warm and cold ambient exposure. Neuroscience 2004;127:385-397.

45 Boulant JA, Dean JB: Temperature receptors in the central nervous system. Annu Rev Physiol 1986;48:639-654.

46 Griffin JD, Boulant JA: Temperature effects on membrane potential and input resistance in rat hypothalamic neurones. J Physiol 1995; 488:407-418.

47 Kelso SR, Boulant JA: Effect of synaptic blockade on thermosensitive neurons in hypothalamic tissue slices. Am J Physiol 1982;243: R480-490.

48 Nakamura K, Morrison SF: Preoptic mechanism for cold-defensive responses to skin cooling. J Physiol 2008;586:2611-2620.

49 Nakamura K, Morrison SF: A thermosensory pathway that controls body temperature. Nat Neurosci 2008;11:62-71.

50 Zaretskaia MV, Zaretsky DV, Shekhar A, DiMicco JA: Chemical stimulation of the dorsomedial hypothalamus evokes non-shivering thermogenesis in anesthetized rats. Brain Res 2002;928:113-125.

51 Zaretskaia MV, Zaretsky DV, DiMicco JA Role of the dorsomedial hypothalamus in thermogenesis and tachycardia caused by microinjection of prostaglandin E2 into the preoptic area in anesthetized rats. Neurosci Lett 2003;340:1-4.

52 Madden CJ, Morrison SF: Excitatory amino acid receptors in the dorsomedial hypothalamus mediate prostaglandin-evoked thermogenesis in brown adipose tissue. Am J Physiol Regul Integr Comp Physiol 2004;286:R320R325.

53 Nakamura K, Morrison SF: Central efferent pathways mediating skin cooling-evoked sympathetic thermogenesis in brown adipose tissue. Am J Physiol Regul Integr Comp Physiol 2007;292:R127-R136.
54 Zhang Y, Kerman I, Laque A, Nguyen P, Faouzi M, Louis G, Jones J, Rhodes C, Münzberg $\mathrm{H}$ : Leptin-receptor-expressing neurons in the dorsomedial hypothalamus and median preoptic area regulate sympathetic brown adipose tissue circuits. J Neurosci 2011;31: 1873-1884.

55 Rezai-Zadeh K, Yu S, Jiang Y, Laque A, Schwartzenburg C, Morrison CD, Derbenev AV, Zsombok A, Münzberg H: Leptin receptor neurons in the dorsomedial hypothalamus are key regulators of energy expenditure and body weight, but not food intake. Mol Metab 2014;3:681-693.

56 Anand BK, Brobeck JR: Localization of a "feeding center" in the hypothalamus of the rat. Proc Soc Exp Biol Med 1951;77:323-324.

57 Anand BK, Brobeck JR: Hypothalamic control of food intake in rats and cats. Yale J Biol Med 1951;24:123-140.

58 Bergen HT, Mizuno TM, Taylor J, Mobbs CV: Hyperphagia and weight gain after gold-thioglucose: relation to hypothalamic neuropeptide $\mathrm{Y}$ and proopiomelanocortin. Endocrinology 1998;139:4483-4488.

59 Hamilton CL: Interactions of food intake and temperature regulation in the rat. J Comp Physiol Psychol 1963;56:476-488.

60 Wang D, He X, Zhao Z, Feng Q, Lin R, Sun Y, Ding T, Xu F, Luo M, Zhan C: Whole-brain mapping of the direct inputs and axonal projections of POMC and AgRP neurons. Front Neuroanat 2015;9:40.

61 Simerly RB, Swanson LW: Projections of the medial preoptic nucleus: a Phaseolus vulgaris leucoagglutinin anterograde tract-tracing study in the rat. J Comp Neurol 1988;270:209-242.

62 Krashes MJ, Koda S, Ye C, Rogan SC, Adams AC, Cusher DS, Maratos-Flier E, Roth BL, Lowell BB: Rapid, reversible activation of AgRP neurons drives feeding behavior in mice. J Clin Invest 2011;121:1424-1428.

63 Ste Marie L, Miura GI, Marsh DJ, Yagaloff K, Palmiter RD: A metabolic defect promotes obesity in mice lacking melanocortin- 4 receptors. Proc Natl Acad Sci USA 2000;97:12339-12344.

64 Monge-Roffarello B, Labbe SM, Lenglos C, Caron A, Lanfray D, Samson P, Richard D: The medial preoptic nucleus as a site of the thermogenic and metabolic actions of melanotan II in male rats. Am J Physiol Regul Integr Comp Physiol 2014;307:R158-R166.

65 Kong D, Tong Q, Ye C, Koda S, Fuller PM, Krashes MJ, Vong L, Ray RS, Olson DP, Lowell BB: GABAergic RIP-Cre neurons in the arcuate nucleus selectively regulate energy expenditure. Cell 2012;151:645-657.

66 Harris GC, Wimmer M, Aston-Jones G: A role for lateral hypothalamic orexin neurons in reward seeking. Nature 2005;437:556-559.

67 Sakurai T, Amemiya A, Ishii M, Matsuzaki I, Chemelli RM, Tanaka H, Williams SC, Richardson JA, Kozlowski GP, Wilson S, et al: Orexins and orexin receptors: a family of hypothalamic neuropeptides and G proteincoupled receptors that regulate feeding behavior. Cell 1998;92:573-585.
The Hypothalamic Preoptic Area and Body Weight Control
Neuroendocrinology 2018;106:187-194 DOI: $10.1159 / 000479875$ 
68 Berthoud HR, Patterson LM, Sutton GM, Morrison C, Zheng H: Orexin inputs to caudal raphe neurons involved in thermal, cardiovascular, and gastrointestinal regulation. Histochem Cell Biol 2005;123:147-156.

69 Tupone D, Madden CJ, Cano G, Morrison SF: An orexinergic projection from perifornical hypothalamus to raphe pallidus increases rat brown adipose tissue thermogenesis. J Neurosci 2011;31:15944-15955.

70 Ek M, Arias C, Sawchenko P, Ericsson-Dahlstrand A: Distribution of the EP3 prostaglan$\operatorname{din} \mathrm{E}(2)$ receptor subtype in the rat brain: relationship to sites of interleukin-1-induced cellular responsiveness. J Comp Neurol 2000; 428:5-20.

71 Orikasa C, Kondo Y, Hayashi S, McEwen BS, Sakuma Y: Sexually dimorphic expression of estrogen receptor beta in the anteroventral periventricular nucleus of the rat preoptic area: implication in luteinizing hormone surge. Proc Natl Acad Sci USA 2002;99:33063311.

72 Lundius EG, Sanchez-Alavez M, Ghochani Y, Klaus J, Tabarean IV: Histamine influences body temperature by acting at $\mathrm{H} 1$ and $\mathrm{H} 3$ receptors on distinct populations of preoptic neurons. J Neurosci 2010;30:4369-4381.
73 Cravo RM, Margatho LO, Osborne-Lawrence S, Donato J Jr, Atkin S, Bookout AL, Rovinsky S, Frazao R, Lee CE, Gautron L, et al: Characterization of Kiss1 neurons using transgenic mouse models. Neuroscience 2011;173:3756.

74 Dimitrov EL, Kim YY, Usdin TB: Regulation of hypothalamic signaling by tuberoinfundibular peptide of 39 residues is critical for the response to cold: a novel peptidergic mechanism of thermoregulation. J Neurosci 2011; 31:18166-18179.

75 McCarren HS, Chalifoux MR, Han B, Moore JT, Meng QC, Baron-Hionis N, SedighSarvestani M, Contreras D, Beck SG, Kelz MB: $\alpha_{2}$-Adrenergic stimulation of the ventrolateral preoptic nucleus destabilizes the anesthetic state. J Neurosci 2014;34:16385-16396.

76 McHenry JA, Otis JM, Rossi MA, Robinson JE, Kosyk O, Miller NW, McElligott ZA, Budygin EA, Rubinow DR, Stuber GD: Hormonal gain control of a medial preoptic area social reward circuit. Nat Neurosci 2017;20: 449-458.

77 Boulant JA, Silva NL: Neuronal sensitivities in preoptic tissue slices: interactions among homeostatic systems. Brain Res Bull 1988;20: 871-878.
78 Stocker SD, Toney GM: Median preoptic neurones projecting to the hypothalamic paraventricular nucleus respond to osmotic, circulating Ang II and baroreceptor input in the rat. J Physiol 2005;568:599-615.

79 Nakashima T, Hori T, Kiyohara T, Shibata M: Osmosensitivity of preoptic thermosensitive neurons in hypothalamic slices in vitro. Pflugers Arch 1985;405:112-117.

80 Silva NL, Boulant JA: Effects of osmotic pressure, glucose, and temperature on neurons in preoptic tissue slices. Am J Physiol 1984; 247:R335-R345.

81 Almeida MC, Vizin RC, Carrettiero DC: Current understanding on the neurophysiology of behavioral thermoregulation. Temperature (Austin) 2015;2:483-490.

82 Santollo J, Torregrossa AM, Eckel LA: Estradiol acts in the medial preoptic area, arcuate nucleus, and dorsal raphe nucleus to reduce food intake in ovariectomized rats. Horm Behav 2011;60:86-93.

83 Kim JS, Rizwan MZ, Clegg DJ, Anderson GM: Leptin signaling is not required for anorexigenic estradiol effects in female mice. Endocrinology 2016;157:1991-2001. 